\title{
Drinking Age Policy Implementation and the Practice of Federal Law in the United States
}

\author{
Godwin Ihemeje \\ College of Arts \& Sciences \\ Albany State University \\ United States \\ Grace Ihemeje \\ College of Health Sciences, \\ Georgia State University \\ United States
}

Received: July 30, 2019 Accepted: April 22, 2020 Online published: April 30, 2020

doi:10.5296/jpag.v10i2.15173～URL: https://doi.org/10.5296/jpag.v10i2.15173

\begin{abstract}
Readjusting a standard or already legalized national drinking age, particularly, in the United States, has been a matter of concern to scholars of political science and health sciences. It is instructive to note that the national legal drinking age of 21 years is a primary alcohol-control policy initiated and implemented since 1985 in the United States. Different groups have raised public debate on the minimum drinking age and proposed reducing it to 18 years. However, recent trends in alcohol drinking and related consequences, comparative effect of the minimum legal drinking ages of 21 years and 18 years, research on alcohol consumption among high school and college students related to minimum legal drinking age are critically reviewed, using secondary data sources. This article therefore seeks to support the minimum drinking age of 21 years, rather than lowering it to 18 years. Concerted interventional roles are essential by the assistance of non-governmental organizations, public health experts, legal experts, and public office holders; for the purpose of influencing healthy decisions about alcohol among the early adults and thereby leading to reduction in alcohol consumption and its negative impacts.
\end{abstract}

Keywords: alcohol, concerted interventional roles, drinking age policy, early adults, United States of America. 


\section{Introduction}

The lowering of drinking age policy in America has been a serious concern among political scientists, public policy analysts, and health practitioners (Knight, et al. 2003; Nelson et al. 2005; Wechsler, 2000; and Welsher \& Nelson, 2010). In the studies conducted by public health scholars with the view to tracing the historical implementation of drinking age for the youths, they reported that:

Since 1984, the national minimum legal drinking age in the United States has been 21 years. During the intervening 25 years there have been periodic efforts to lower the minimum legal drinking age, including recent legislation introduced in 7 states, although none of these bills have been enacted. In 2008 a group of university and college presidents expressed their discontent with the minimum legal drinking age of 21 years by signing on to the Amethyst Initiative, a much publicized advocacy effort to encourage public debate about lowering the drinking age. This group of college presidents, and their partner organization, Choose Responsibility, proposed reducing the minimum legal drinking age to 18 years. This policy change is a central feature of a campaign its organizers contend will help young adults aged 18 to 20 years make healthy decisions about alcohol and lead to reductions in drinking and its negative effects. Because the consequences of alcohol use are considerable, and changes in the minimum legal drinking age may have important ramifications or complicating results (words in bold are authors') for health and safety, this issue requires serious consideration and participation from the public health community (Wechsler and Nelson, 2000).

Detailed historical accounts about the United States drinking age legislation and enforcements reveal developmental milestones and provide more insights, and systematically captured along these lines:

Between 1776 and 1920, drinking age varied from state-to-state, with most states not enforcing a drinking age at all; between 1920 and 1930 - particularly from the time (1920) when the $18^{\text {th }}$ Amendment to the United States Constitution was ratified-there was a prohibition on the sale and consumption of alcoholic beverages in the United States completely; the post prohibition occurred between 1933 and 1960 -following the ratification of the $21^{\text {st }}$ Amendment to the United States Constitution in December 1933 - there was a repeal on the prohibition of alcohol consumption in which most states set their drinking age to 21 but some set it lower, by the late 1960s and 1970s nearly all states had lowered drinking age to 18 years - this led to a huge increase in alcohol-related car accidents and drunk driving was deemed a public health crisis while over two-thirds of car accidents involving persons aged 16 to 20 were alcohol-related during this period, and lastly was the period 1984-2014 in which the minimum drinking age was raised to 21 years - specifically motivated in response to the drunk driving epidemic of the 1970s, President Ronald Reagan passed the Minimum Drinking Age Act in July 1984, a law that mandated states increase the drinking age to 21 (Tietjan, 2014). 
In view of the historical implementations of drinking age and the recent negative consequences that it poses on the American society, more than usually, inducing incessant risky behaviors and endangering of lives of young adults pertinently informs this article.

We classify the discussions into six sections. The first section focuses on the introduction which has been established in the preceding paragraphs. The second and third sections deal with review of minimum drinking age in the United States, and alcohol consumption and public health awareness. The fourth and fifth sections compare high school and college students' minimum drinking ages and consequences, as well as various arguments about the minimum drinking age, and the sixth section concludes the essay.

\section{Review: The Minimum Drinking Age in the United States of America}

Minimum legal drinking age laws have been a primary alcohol-control method in the United States for 75 years (Wechsler and Nelson, 2010). Just as noted earlier, following the 21st Amendment to the US Constitution that repealed Prohibition in 1933, most states set a minimum legal drinking age of 21 years, although the specific provisions of the law in each state varied (Wechsler and Sands, 1980). For example, 45 states have exceptions to allow underage consumption of alcohol under certain circumstances while five states (Alabama, Arkansas, Idaho, New Hampshire, and West Virginia) have no such exceptions (ProCons.org, 2016).

\section{Alcohol Consumption and Public Health Awareness}

Alcohol consumption is a public issue. According to the survey conducted in the United States by the National Institute on Alcohol Abuse and Alcoholism, it shows that $86.4 \%$ of people ages 18 or older reported that they drank alcohol at some point in their lifetime; $70.1 \%$ reported that they drank in the past year; $56.0 \%$ reported that they drank in the past month, while in $2015,26.9 \%$ of people ages 18 or older reported that they engaged in binge drinking in the past month; $7.0 \%$ reported that they engaged in heavy alcohol use in the past month (Anthenelli et al., 2018). Furthermore, editors of the National Institute on Alcohol Abuse and Alcoholism opine that alcohol use disorder (AUD) is a chronic, relapsing brain disease characterized by a reduced ability to stop or control alcohol use despite negative social, work, or health consequences. Often, it co-occurs and interacts with post-traumatic stress disorder (PTSD), which may develop after experiencing or witnessing a life-threatening event, such as combat, a natural disaster, a car accident, or sexual assault, and can result in shock, confusion, anger, and anxiety (Anthenelli et al., 2018).

\section{Comparing High Schools and College Students'Alcohol Consumption Rates}

Current drinking is defined as consuming one or more alcoholic drink on $\geq 1$ day during the past 30 days. Binge drinking was defined as consuming five or more alcoholic drinks in a row on $\geq 1$ day during the past 30 days (Esser et al., 2017).

Report has it that each year from 2006 to 2010, excessive alcohol consumption was responsible for approximately 4,300 deaths among persons aged <21 years, and, in 2010, underage drinking cost the United States $\$ 24.3$ billion (Esser et al., 2017). This report is justified with 
the studies conducted among high school students with respect to alcohol in-take, and the studies have shown that the overall prevalence of current alcohol drinking among U.S. high school students declined significantly from $50.8 \%$ in 1991 to $44.7 \%$ in 2007 , then further declined to $32.8 \%$ in 2015 . The prevalence of binge drinking increased from $31.3 \%$ in 1991 to $31.5 \%$ in 1999, then, declined significantly to $17.7 \%$ in 2015. However, in 2015, approximately one in three high school students drank alcohol during the past 30 days and one in six was binge drinkers. Most high school students who drank alcohol (57.8\%) were also binge drinkers, and more than two in five binge drinkers consumed eight or more drinks in a row (Esser et al. 2017). Widespread use of evidence-based strategies for preventing excessive drinking (e.g., increasing alcohol taxes, regulating alcohol outlet density, and having commercial host liability laws) could help reduce underage drinking and related harms (Esser et al. 2017).

Based on studies conducted among College students, it is revealed that they are heavy drinkers as a group, but drinking behavior varies widely from across colleges. College environments that afford easy access to low-cost alcohol, have few policies restricting accessibility to alcohol, and have lax enforcement of existing policies create the conditions for heavy drinking among college students. The Safe and Drug-Free Schools and Communities Act requires college administrators to enforce the minimum legal drinking age of 21 years, a restriction that targets approximately half of the traditional college student population. However, surveys of college administrators indicate that enforcement of alcohol policies at most colleges is limited, and colleges tend to focus their prevention efforts on educational programs for students (Wechsler and Nelson, 2010).

\section{Arguments: Reduction of Minimum Drinking Age and Its Consequences}

Various arguments regarding the reduction of minimum drinking age are examined. First, a primary argument in favour of reducing the minimum legal drinking age is to prevent young people's view of drinking alcohol as a rebellious activity. If they were able to consume alcohol at a younger age, such as 18, they could have their first legal drink while still living with their parents. This might limit the risk that students will binge drink in either high school or college, as alcohol will no longer have a forbidden fruit appeal (Harte, 2018).

Second, New Jersey State Assemblyman, Michael Patrick Carroll introduced a bill to make 18 the legal drinking age in the Garden State, arguing that "if young adults are old enough to serve in the military; they should be old enough to buy alcohol legally" (CBS New York News, 2016). The New Jersey State Assembly-man buttressed, "if you're old enough to join the military, as two of my sons have, and to be handed an M4 and to be sent on lethal missions where you're risking your life, it seems to be you're adult enough to make the relatively trivial decision whether to buy a six pack of beer" (CBS New York News, 2016).

Third, essentially fuelled in part by the high-profile national media attention garnered by the Amethyst Initiative and Choose Responsibility, activists and policymakers in several states, including Kentucky, Wisconsin, South Carolina, Missouri, South Dakota, Minnesota, and Vermont, have put forth various legislative proposals to lower their state's drinking age from 21 to 18 , though no state has adopted a lower minimum legal drinking age, yet (Carpenter 
and Dobkin, 2011).

According to results from the 2006-2007 National Health Interview Survey, adults age 18-25 report that on average they drank in 36 days in the previous year and typically consumed 5.1 drinks on the days they drank. If consumed at a single sitting, five drinks meets the clinical definition of "binge" or "heavy episodic" drinking. This consumption contributes to a substantial public health problem: five drinks for a 160-pound man with a limited time between drinks leads to a blood alcohol concentration of about $0.12 \%$ and results in moderate to severe impairments in coordination, concentration, reflexes, reaction time, depth perception, and peripheral vision. For comparison, the legal limit for driving in the United States is generally $0.08 \%$ blood alcohol content (Carpenter and Dobkin, 2011).

Undoubtedly, motor vehicle accidents (the leading cause of death and injury in this age group), homicides, suicides, falls, and other accidents are all strongly associated with alcohol consumption (Bonnie and O' Connell, 2004). This is justified by the fact that around $80 \%$ of deaths among young adults are due to these "external" causes (as opposed to cancer, infectious disease, or other "internal" causes), policies that change the ways and extent to which young people consume alcohol have the potential to affect the mortality rate of this population substantially.

An extensive public health literature documents the strong correlation between alcohol consumption and adverse effects, but estimates from these studies are of limited value for determining whether the minimum legal drinking age should be set at 18,21, or some other ages. Their main limitation is that the correlation between alcohol consumption and adverse events is probably due in part to factors other than alcohol consumption, such as variation across individuals in their tolerance for risk. People with a high tolerance for risk may be more likely both to drink heavily and to put themselves in danger in other ways, such as driving recklessly, or even when they are sober. If this is the case, then predictions based on these correlations of how much public policy might reduce the harms of alcohol consumption will be biased upwards (Carpenter and Dobkin, 2011).

\section{Conclusion}

Contrary to the assertion of the Amethyst Initiative, heavy alcohol consumption among adolescents is a common problem across Europe. Frequent binge drinking among adolescents aged 15 to 16 years in many countries occurs at more than double the rate as in the United States (Wechsler and Nelson, 2010).

Drunk driving is an especially dangerous activity for young people. Minimum age drinking laws have been effective at limiting its danger. Between $1975-2016$, minimum drinking age laws saved more than 30,000 lives according to the National Highway Traffic Safety Administration (Harte, 2018). A lower drinking age could also have negative health effects since adolescence is a key period for brain development. The hippocampus is a part of the brain that plays a major role in memory development. According to research from the University of California-San Diego, volumes of the hippocampus were significantly smaller in adolescents with alcohol use problems, potentially leading to memory problems (Harte, 
2018).

Currently, the Federal Law provides for the following exceptions under the original legislation:

... the possession of alcohol for an established religious purpose; when accompanied by a parent, spouse or legal guardian age 21 or older; for medical purposes when prescribed or administered by a licensed physician, pharmacist, dentist, nurse, hospital or medical institution; in private clubs or establishments; or to the sale, handling, transport, or service in dispensing of any alcoholic beverage pursuant to lawful employment of a person under the age of twenty-one years by a duly licensed manufacturer, wholesaler, or retailer of alcoholic beverages (Choose Responsibility, n.d.).

Federal law or public policy can be very controversial in the United States regulatory calculations due to jurisdictional authorities that both states and federal governments enjoy within the purview of the Constitution. For instance, after expressing and apportioning sanctions on states non-compliance with the national drinking age by October 1, 1986, during President Regan's administration, such policy action was criticized for infringing on the rights of the various independent states (Liebschutz, 1985). Accordingly, Senator Max Baucus who was equipped with the federal law practice in the United States observed the contrary view:

The real issue is whether the federal Government should intrude into area that has traditionally and appropriately been left to the states and force them into accepting its solution to the problem of drunk-driving (U.S. Congress, 1984).

The operationalization of governmental policy in an ideal federal system arrangement like that of the United States is a matter of choice rather than compulsion, to complying with a federal solution to a problem. Informed by this view, the national declaration drinking age of 21 years for about thirty-four (34) years ago appears either more-effective or less-effective among the distinct fifty (50) States.

It is evidently clear that there is need for more campaigns on the drinking age among the youths at age 21 years and not less; and that would help to reduce the risk factors associated with it, in the country. More advocacy work has to be carried out by researchers, non-governmental organizations, public health professionals, and public officials (at the federal, state and local government levels). 


\section{References}

Anthenelli, R. M., Brady, K. I., Grandisson, L. \& Roach, D. (2018). Co-Occurring Alcohol Use Disorder and Post-Traumatic Stress Disorder. The Journal of the National Institute on Alcohol Abuse and Alcoholism, 39(2).

Bonnie, R. J., \& O'Connell, M. E. (eds). (2004). Reducing Underage Drinking: A Collective Responsibility. Washington, DC: National Academics Affairs.

Carpenter, C., \& Dobkin, C. (2011). The National Legal Drinking Age and Public Health. Journal of Economic Perspective, 25(2), 133-156. https://doi.org/10.1257/jep.25.2.133

CBS New York News. (2016). New Jersey State Assemblyman Introduced a Bill to Change the Legal Drinking Age to 18 years. CBS New York News, February 24: https://newyork.cbslocal.com/2016/02/24/new-jersey-drinking-age/ (Accessed 7/29/2019)

Choose Responsibility (2019). Lowering the Drinking Age. http://www.chooseresponsibility.org/policy_change/ (Accessed 7/29/2019)

Esser, M. B., Clayton, H., Demissie, Z., Kenny, D., \& Brewer, R. D. (2017). Centers for Disease Control and Prevention - Morbidity and Mortality Weekly Report. May 12, 66(18), 474-478. https://doi.org/10.15585/mmwr.mm6618a4

Harte, M. (2018). Lower Drinking Age Proposals Contain Various Risks. Marquette Wire Columnist, 7.

Knight, J. R., Harris, S. K., Shemit, L., Kelly, K., Van Hook, S., \& Wechsler, H. (2003). Heavy Drinking and Alcohol Policy Enforcement in a State-wide Public College System. Journal Studies of Alcohol, 64(5), 696-703. https://doi.org/10.15288/jsa.2003.64.696

Liebschutz, S. F. (1985). The National Minimum Drinking Age-Law. Publius: The Journal of Federalism, 15(3), 39-52. https://doi.org/10.1093/oxfordjournals.pubjof.a037556

Nelson, T. F., Naimi, T. S., Brewer, R. D., \& Wechsler, H. (2005). The State Sets the Rate: The Relationship Among State-Specific College Binge Drinking, State Binge Drinking Rate, and Selected State Alcohol Control Policies. American Journal of Public Health, 95(3), 441-446. https://doi.org/10.2105/AJPH.2004.043810

PROCON.ORG - Pros and Cons of Current Issues (2016) 45 States That Allow Underage (under 21) Alcohol Consumption. https://drinking-age-com/45-states-that-allow-Consumption (Accessed 7/28/2019)

Tietjan, D. (2014). Why 21? A Look at Our Nation's Drinking Age.

United States' Congress, Senate (1984). Congressional Record, $8^{\text {th }}$ Congress and $2^{\text {nd }}$ Session, 1300 pt. $99,8233$.

Wechsler, H., \& Nelson, T. F. (2010). Will Increasing Alcohol Availability by Lowering the Minimum Legal Drinking Age Decrease Drinking and Related Consequences Among Youths? 


\section{Macrothink}

Journal of Public Administration and Governance ISSN 2161-7104 2020, Vol. 10, No. 2

American Journal of Public Health, June, 100(6), 986-992. https://doi.org/10.2105/AJPH.2009.178004

Wechsler, H., Kuo, M., Lee, H., \& Dewalall, G. W. (2000). Environmental Correlates of Underage Alcohol Use and Related Problems of College Students. American Journal of Preventive Medicine, 19(1), 24-29. https://doi.org/10.1016/S0749-3797(00)00163-X

\section{Copyright Disclaimer}

Copyright for this article is retained by the author(s), with first publication rights granted to the journal.

This is an open-access article distributed under the terms and conditions of the Creative Commons Attribution license (http://creativecommons.org/licenses/by/4.0/). 